Revista Iberoamericana, Vol. LXXVIII, Núms. 238-239, Enero-Junio 2012, 247-258

\title{
MURMULLOS FEMENINOS EN LA CIENCIA-FICCIÓN ARGENTINA. PROBLEMAS DE GENDER Y GENRE
}

\author{
POR \\ María Magdalena Uzín \\ Universidad Nacional de Córdoba
}

Este trabajo aborda, desde una sociosemiótica con perspectiva de género, el entrecruzamiento entre dos problemas teóricos referidos a la ciencia ficción argentina: el primero, el acercamiento al género -que cuenta con una larga y rica tradición localpor parte de autores reconocidos como pertenecientes al "no-género", es decir, cuya obra en general no es presentada con la etiqueta de la ciencia ficción; se trata aquí de un problema de definición de géneros (genre) literarios y su arbitraria jerarquización. El segundo problema tiene que ver con la otra acepción del término, indagando en la relación entre géneros (gender) sexuales y ciencia-ficción, tanto desde la presencia de autoras dentro del canon de la ciencia-ficción a nivel local y global, como desde la presencia (o significativa ausencia) en las obras de la voz y la palabra femeninas como nudo problemático o disparador simbólico. Para ello se abordarán obras que se acercan en diversa medida a la ciencia-ficción de autores con una relación más o menos distante o cercana con el género en los siguientes textos de escritores argentinos: Pubis Angelical, de Manuel Puig (General Villegas, 1932-1990); La ciudad ausente, de Ricardo Piglia (Adrogué, 1941-); El congreso de literatura, de César Aira (Coronel Pringles,1949-); Cola de lagartija, de Luisa Valenzuela (Buenos Aires, 1938-); Kalpa imperial, Bajo las jubeas en flor, de Angélica Gorodischer (Buenos Aires, 1928-). La selección incluye escritores que no se identifican como "autores de ciencia-ficción” (en el caso de Puig, Piglia, Aira y Valenzuela) pero que lo abordan de manera ocasional; y a una escritora reconocida como "autora de ciencia-ficción”(Gorodischer), aunque sus obras no siempre pertenecen al género (es autora de excelentes relatos policiales, por ejemplo). Esta opción nos permitirá analizar desde las obras (y no desde una clasificación dada a priori) cómo se define el género, qué lugar ocupa un “nombre de autor” en la definición del mismo, qué operaciones se llevan a cabo en esos cruces genéricos.

La literatura de ciencia-ficción enfrenta a la teoría literaria con debates siempre abiertos en torno a categorías centrales del campo disciplinar, revelando su complejidad, sus cruces y su fluidez. Un problema fundamental planteado por la ciencia-ficción es la definición de un género literario, en sus rasgos específicos, y en cuanto a los límites que incluyen/excluyen las obras particulares del universo discursivo de la ciencia-ficción. 
Junto a éste, se plantea el problema de la (no) autonomía de los fenómenos literarios ante las instituciones del mercado editorial y el campo intelectual.

Las definiciones del género configuran un espectro amplísimo, desde la que afirma que "[s]cience fiction is anything published as science fiction" (Norman Spinard citado en Stableford, Clute y Nicholls 311), que hace depender la especificidad del género de las clasificaciones del mercado editorial, dejando de lado rasgos específicos, formales o temáticos, necesarios o suficientes para considerar una obra como ciencia-ficción, vinculando así al género más con el campo de la industria cultural que con el campo literario. En el otro extremo del espectro encontramos respuestas altamente formales y restrictivas que establecen condiciones textuales necesarias (temáticas o formales) para que una obra se clasifique o no como ciencia-ficción. Entre éstas, una de las más clásicas es la de Darko Suvin, uno de los primeros teóricos de la literatura en tomar en cuenta a la ciencia-ficción desde la academia, quien desde un marco de pensamiento materialista propone la siguiente definición: "a literary genre whose necessary and sufficient conditions are the presence and interaction of estrangement and cognition, and whose main formal device is an imaginative framework alternative to the author's empirical environment” (citado en Stableford, Clute y Nicholls). Estos rasgos pueden ser reconfigurados, como en la definición de Jeff Prucher,

a genre (of literature, film, etc.) in which the setting differs from our own world (e.g. by the invention of new technology, through contact with aliens, by having a different history, etc.), and in which the difference is based on extrapolations made from one or more changes or suppositions; hence such a genre in which the difference is explained (explicitly or implicitly) in scientific or rational, as opposed to supernatural, terms. (171)

Otro rasgo destacado en numerosas definiciones es la relación con los desarrollos científicos y tecnológicos contemporáneos: "Science fiction is a form of fantastic fiction which exploits the imaginative perspectives of modern science" (Pringle 9); incluso un clásico y respetado autor del género como Asimov lo define en esos términos: “'[H]ard science fiction' [is] stories that feature authentic scientific knowledge and depend upon it for plot development and plot resolution” (Greenberg y Asimov 6). Pero existen definiciones mucho más amplias e inclusivas, con la desventaja de que no ofrecen la posibilidad de delimitar criterios de pertenencia o no al género frente a obras particulares, aunque sí funcionan como elemento de unificación de los múltiples registros que configuran la ciencia-ficción, como la que sugiere que: "Perhaps the crispest definition is that science fiction is a literature of 'what if'? What if we could travel in time? What if we were living on other planets? What if we made contact with alien races? And so on. The starting point is that the writer supposes things are different from how we know them to be” (Evans 9).

Revista Iberoamericana, Vol. LXXVIII, Núms. 238-239,
ISSN 0034-9631 (Impreso) 
Ante esta diversidad de definiciones, conviene retomar algunas de las concepciones teóricas del género, ya no como una normativa o una tipología a priori a la manera decimonónica, sino revisando los presupuestos que constituyen dichas tipologías. En este sentido, G. Genette propone que la definición de un género se da en una particular combinatoria de aspectos temáticos, formales y concernientes a la situación de enunciación (68-69). Así, toda clasificación genérica recurre a criterios heterogéneos que se basan tanto en categorías estéticas como pragmáticas. Otro teórico que se propone revisar la categoría de género es Fredric Jameson, quien se detiene en su función mediadora entre un análisis inmanente, formal, y una perspectiva diacrónica de las formas y la evolución de la vida social (85). Así el género se entiende como portador de una visión de mundo, y esa visión de mundo es entendida como ideologema, como complejo conceptual propio de una época determinada. El género como ideologema es una respuesta activa y una solución imaginaria de las contradicciones objetivas de la época. El análisis se abre así a la "lógica del contenido", a las "materias primas semánticas de la vida social y el lenguaje, las constricciones de determinadas contradicciones sociales, las coyunturas de la clase social [...]” (Jameson 118). En el análisis de Jameson la historia no es la "causa” de determinada configuración genérica o textual, sino que es una limitación, algo que bloquea o clausura cierto número de posibilidades formales disponibles anteriormente, y abre ciertas posibilidades nuevas que pueden o no realizarse. Siguiendo esta línea de pensamiento, Jameson se ocupa en otro momento de la ciencia-ficción en relación a la novela histórica, señalando sus orígenes comunes y el hecho de que la ciencia-ficción "provee una representación ideológica de los conflictos presentes a través de imaginar el futuro" (Reati 15).

Otro elemento que se pone en juego a la hora de definir el género es el nombre de autor. Asimov, Ballard, Phillip K. Dick, son significantes que no sólo remiten a los escritores a los que designan, sino que están ya identificados con la ciencia-ficción de manera casi incuestionable, de modo que ante una nueva obra con ese nombre de autor, la pertenencia al género se da casi por descontada y sería la no-pertenencia al mismo la que habría que señalar y justificar.

Sin embargo, al abordar la historia del género en Argentina, encontramos una situación muy diferente. Esa historia de la ciencia-ficción argentina es extensa, abarcando desde los comienzos del siglo xx, y, aunque sea quizás limitada cuantitativamente, es sin dudas muy rica y productiva en términos cualitativos. Uno de los rasgos diferenciales de esta tradición consiste en que por lo general los autores que abordan el género no lo hacen de manera exclusiva y no se constituyen así como "autores de ciencia-ficción”. Muchos autores canónicos de la literatura argentina de las últimas décadas desarrollan a lo largo de su obra un diálogo interdiscursivo con géneros surgidos de la cultura popular y de masas. Es el caso de los autores que vamos a analizar en esta ocasión: Manuel Puig acudió en sus novelas al melodrama cinematográfico, al bolero y, al menos en la obra que nos ocupa, a la ciencia-ficción; Ricardo Piglia también acude a ella para hacerla

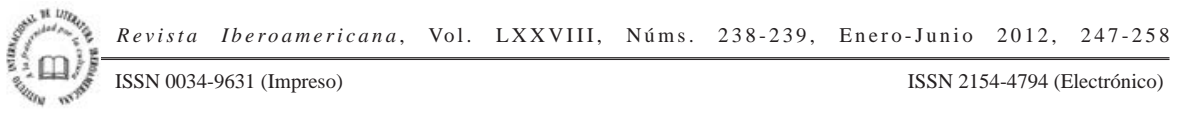


dialogar con la novela histórica y la policial; César Aira usa la parodia para cruzar el género de aventuras, la crítica literaria y la ciencia-ficción; Luisa Valenzuela cruza lo fantástico y ciencia-ficción en una escritura que busca el borramiento de todos los límites y las clasificaciones. Es diferente el caso de Angélica Gorodischer, cuyo nombre de autor sí se identifica fuertemente como ciencia-ficción, aún cuando muchas de sus obras no pertenecen al género.

Lo que estos usos del género están mostrando, entonces, es su potencial significativo: tomando algunos de sus elementos como la relación con la ciencia y la tecnología o la creación de un mundo alternativo (“¿Qué pasaría si...?”), los ponen en juego con otras líneas de sentido. Más o menos ceñidos o alejados del modelo canónico de la ciencia-ficción, estas obras cruzan algunos tópicos del género (el futuro, la máquina, la clonación, la distopía de un poder maligno que domina el mundo, el viaje espacial y temporal), con ejes políticos, en especial los relativos a la constitución de identidades nacionales y de género, esta vez en el sentido de gender, géneros sexuales.

Manuel Puig, Pubis Angelical, 1979

Ésta es la quinta novela de Puig, y la única que se acerca a la ciencia-ficción. En ella continúa el cuestionamiento iniciado en su novela anterior, El beso de la mujer araña, acerca de la matriz heteronormativa, el sistema jerárquico heterosexual excluyente. La novela se sitúa en el año 1975 y cuenta la historia de Ana, una argentina exiliada en México, internada enferma de cáncer, centrándose en sus diálogos con una amiga y un amante argentino también exiliado, defensor de presos políticos. Esas conversaciones abordan cuestiones relativas a las identidades genéricas, nacionales y políticas de los protagonistas: qué es ser argentino, qué es ser peronista y qué es ser mujer son los tópicos reiterados de esos diálogos, situados en un presente identificable con el mundo empírico. Con ellos, y con fragmentos del diario de Ana, se entrecruza una historia desarrollada en dos partes: la de una actriz vienesa de los años cuarenta y su llegada a Hollywood (vagamente inspirada en la historia de Hedy Lamarr ${ }^{1}$ ), reflejada y continuada en la historia, ubicada en el futuro, de W218, una joven “trabajadora sexual” de la "era polar”. Ambas historias están unidas por numerosos detalles, en especial el tópico central: estas mujeres son perseguidas porque tienen la capacidad de leer el pensamiento de todo hombre que las desee y las mire a los ojos. En ambas historias, la mujer es representada como extremadamente sumisa, indefensa ante el amor, incapaz de dominar sus emociones: el estereotipo femenino del melodrama aparentemente incuestionado. Ese poder de leer la mente masculina, sin embargo, es el comienzo de un cambio al hacer evidente para ellas

1 Hedy Lamarr (Viena, 1914-Orlando, Florida, 2000), actriz e ingeniera en telecomunicaciones. Su biografía es, en sí misma, una novela de ciencia-ficción.

$\begin{array}{llll}\text { ISSN 0034-9631 (Impreso) } & \text { ISSN 2154-4794 (Electrónico) }\end{array}$ 
la dominación a la que están sometidas, también presentada en términos estereotipados y melodramáticos. Es justamente el uso de la ciencia-ficción, en un relato que abarca progresivamente más y más espacio en la novela, lo que permite a la vez denunciar la persistencia de ese sistema de dominación y la posibilidad de superarlo. Su persistencia, ya que aún en un futuro distante, pos-catástrofe natural, los estereotipos sobre la feminidad siguen vigentes, la mujer sigue siendo excluída de la razón y encerrada en lo sentimental, valorada sólo por su belleza y convertida legalmente en objeto sexual: la protagonista está cumpliendo su "conscripción" ofreciendo "servicios sexuales" a hombres ancianos, enfermos y "deformes" establecidos por el Estado, mientras que no existe un servicio semejante destinado a mujeres ancianas, enfermas o deformes. Su posibilidad de superación surge, por el contrario, del fracaso de laúnica redención posible en el melodrama para la mujer: el amor romántico y su concreción en el matrimonio. La historia de amor de la joven es falsa, es una conspiración para neutralizar su poder, y conduce a otro tipo de redención. Es enviada a una cárcel subterránea, bajo los hielos polares, junto a peligrosos presos políticos y enfermos contagiosos a los cuales prestaría voluntariamente sus servicios. Esta enfermedad que no se nombra, para la cual no hay vacunas, ${ }^{2}$ termina por llevarla a la agonía. En su lecho de muerte oye el relato delirante de otra enferma, momento donde se construye la propuesta superadora de la novela, en la figura que da título a la novela, el pubis angelical, la anulación de las identidades sexuales. Ese pubis angelical aparece en una mujer que huye de la cárcel y cuyo cuerpo se desmaterializa, para volver a aparecer en una "Plaza del Pueblo" y detener una confrontación armada. Es la desmaterialización del cuerpo, la superación de la heterosexualidad, la anulación de las diferencias sexuales lo que se convierte en "mensaje de paz" política y social, no solamente sexual, al mismo tiempo que es la condición de posibilidad de una autonomía femenina y un redescubrimiento de los lazos filiales femeninos, de la línea matriarcal perdida.

Ricardo Piglia, LA CiUdAd AUSENTE, 1992

Para comenzar, es claro que Piglia es un escritor académico. Reconocido como autor de ficción y como crítico literario, profesor universitario en Argentina y Estados Unidos, sus ficciones siempre incorporan elementos de géneros como el policial y, en el caso de

2 Recordemos que la novela se publica en 1979, es decir que se escribe antes de la aparición del SIDA como enfermedad y como elemento del imaginario social. Esta referencia, así como la imagen final de las mujeres en la "Plaza del Pueblo", que puede remitirse a la imagen de las Madres de la Plaza de Mayo y su resistencia a la dictadura militar de 1976-1983 en Argentina. Estos son elementos que reafirman otro rasgo con el que suele definirse la ciencia-ficción: su poder "anticipatorio", tal vez dado por la capacidad de la ficción literaria de captar elementos que apenas aparecen o se insinúan en el discurso social de un momento dado y "amplificar" sus efectos.

ISSN 0034-9631 (Impreso) 
la novela que nos interesa, la ciencia-ficción, en un contexto discursivo complejo que se relaciona con modelos literarios y teorías lingüísticas, literarias, semióticas, desarrolladas e integradas como elementos de la trama. Una trama que se construye en torno a relatos, variaciones de relatos, reconstrucciones de relatos: la relación conflictiva entre la voz, la palabra y el sentido. Tener voz no implica dominar las palabras, conocer palabras no implica poder comunicarse, voz y palabra no son suficientes para producir sentido. Los sentidos se generan y producen en los relatos y sus variaciones.

La historia se desarrolla a partir de la presencia de una Máquina productora de relatos, la máquina de Macedonio, encerrada en un Museo, ${ }^{3}$ cuyas grabaciones se distribuyen clandestinamente. El origen de la máquina parte de algunos datos biográficos del escritor argentino Macedonio Fernánadez, ${ }^{4}$ ficcionalizados en una historia de amor: desesperado ante la muerte de su joven esposa, Elena Obieta, Macedonio abandona todo y construye esta máquina para retenerla: "ella era la Eterna, el río del relato, la voz interminable que mantenía vivo el recuerdo" (49). La máquina forma parte de la "serie de los Aquenó”, cuya definición parece la contrapartida de aquella que caracterizaba a la ciencia-ficción a partir de la pregunta ¿qué pasaría si...?: los Aquenó son aquellos “aparatos a cuyo funionamiento precede siempre una expectativa incrédula” (44).

Los relatos producidos son clandestinos porque se trata de una sociedad situada en una temporalidad incierta (sólo uno de los relatos proporciona indicios de una ubicación en el futuro, contradictorios y difusos por otra parte), en la que el estado se ocupa de controlar obsesiva y cuidadosamente el lenguaje y la circulación de los relatos, es decir, del sentido: "el estado mental, la realidad imaginaria, todos pensamos como ellos piensan y nos imaginamos lo que ellos quieren que nos imaginemos” (152); la policía se ocupa de "controlar el principio de realidad" (98).

Desde esta máquina, que es una mujer que produce relatos como la única manera de resistir esa dominación político-lingüístico-policial, se multiplican-como los relatoslos personajes de mujeres que escapan de una u otra manera al lenguaje establecido y su construcción de la realidad. Uno de los relatos transmitidos desde el museo cuenta la historia de "La nena" que es "una máquina humana, sin sentimientos y sin esperanza" (58), que sólo dispone de un lenguaje “abstracto, despersonalizado" (56). Imposibilitada de comunicarse, estigmatizada como loca, es el padre el que, a través de infinitas variaciones de un mismo relato, consigue devolverla al lenguaje, al sentido, al orden temporal en una propuesta bastante lacaniana de la constitución del sujeto a través de lenguaje como Ley del Padre.

Museo, Clínica, Aquenó: con mayúsculas en el original.

4 Macedonio Fernández, (Buenos Aires, 1874-1952), escritor antirrealista, de gran influencia en las vanguardias argentinas y en Jorge Luis Borges en particular.

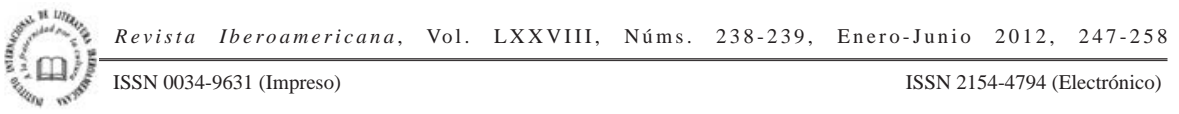


Este personaje se refleja, se repite con variaciones, en el de Julia, la joven que viene de la Clínica psiquiátrica y se ofrece a guiar al protagonista en su investigación sobre la máquina.

La loca, la prostituta y la niña son las figuras casi arquetípicas con las que se construyen en esta novela los personajes de las mujeres, quienes son las que traen, a veces a costa de su vida, los fragmentos de información con los que el protagonista va construyendo su propio relato. En uno de ellos se menciona "la leyenda de la mujer que iba a venir a salvarnos”, "una Eva futura” (84-85), leyenda que nunca se cristaliza en el texto. El último fragmento de la novela condensa esas figuras arquetípicas en el relato autoconsciente de la máquina que por primera vez deja oír su propia voz, se describe a sí misma encerrada en el Museo clausurado, sola, "como un cadáver embalsamado”. Esa referencia a Eva Perón ${ }^{5}$ se desarrolla en el relato tras una serie de identificaciones de la máquina: "he sido lo que he sido, una loca argentina a la que han dejado sola" (172-73)-frase donde "loca” pone en juego su doble acepción coloquial argentina, como demente y como puta. La máquina es Amalia (novela fundacional argentina del siglo XIX), es Molly (Ulises de Joyce, autor que es una referencia reiterada en la novela), es Hipólita (personaje de Roberto Arlt en Los siete locos), es Temple Drake (personaje de Santuario, de Faulkner) en una serie que establece una genealogía literaria, un canon donde los personajes femeninos son la corporización de identidades y conflictos sociales y nacionales. El último eslabón de esta serie, el más desarrollado narrativamente, es Eva Perón, en las imágenes de la luchadora y defensora de los humildes y del cadáver embalsamado oculto y adorado a la vez. Todos ellos se condensan en Ada Eva María Phalcon, la prostituta que escucha a Satanás e ingresa a un convento, pero ninguno de estos personajes puede proponer una redención más allá de sí mismas. No hay una “salvación” posible, sólo una resistencia solitaria, agotadora, de la máquina que en su monólogo final (en una reminiscencia del último capítulo del Ulises) insiste: "voy a seguir, hasta el borde del agua, sí” (178).

\footnotetext{
5 Eva Perón (María Eva Duarte de Perón, Junín/Los Toldos, 1919-Buenos Aires, 1952), actriz en su juventud, esposa del Presidente Juan Domingo Perón. Como Primera Dama, llevó adelante la Fundación Eva Perón, que se ocupaba de asistir y promover a los sectores sociales más desprotegidos. Esta labor y su identificación con los más humildes le valieron la adoración de sus "descamisados", el título de "abanderada de los humildes” y el rechazo de las clases altas. Murió de cáncer, muy joven, en 1952. Su cadáver fue embalsamado y la "Revolución Libertadora” que depuso a Perón en 1955 lo secuestró; permaneció desaparecido por catorce años, dando lugar a rumores y relatos de todo tipo. El cadáver fue devuelto a Perón, por entonces exiliado en España, en 1971, con un dedo cortado intencionalmente, y retornó a Argentina en 1974. Actualmente descansa en el tradicional cementerio de La Recoleta, en la ciudad de Buenos Aires. Esta historia ha sido tratada en numerosas obras literarias argentinas, por ejemplo el relato "Esa mujer” (1963), de Rodolfo Walsh (Choele-Choel, 1927, desaparecido el 25 de marzo de 1977) y la novela Santa Evita (1995), de Tomás Eloy Martínez (Tucumán, 1934-2010).
}

Revista Iberoamericana, Vol. LXXVIII, Núms. 238-239, Enero-Junio 2012, 247-258
ISSN 2154-4794 (Electrónico) 
Luisa Valenzuela, Cola de LagartiJa, 1981-1983

La novela de Valenzuela, escrita durante la dictadura militar de 1976-1983, también acude a diferentes registros y géneros para narrar una historia que transcurre en dos planos de realidad diferentes. El primero, un registro con referencias políticas, históricas y geográficas identificables al momento de la escritura y publicación de la obra, que cuenta la historia de una escritora, su relación con militantes y sus intentos de ayudar a perseguidos políticos a salir del país. El segundo registro, entrecruzado con el primero, constantemente interrogado por los personajes de aquél, oscila entre el fantástico y la ciencia-ficción en un movimiento difícil de clasificar. Este registro toma la figura de un personaje siniestro de la historia política argentina, José López Rega, ${ }^{6}$ quien fue secretario de Perón ${ }^{7}$ en su exilio y llegó a ser Ministro de Bienestar Social de su esposa María Estela Martínez (Isabel) cuando ésta asumió la presidencia a la muerte de Perón, creando la Triple A (Alianza Argentina Anticomunista) que dio origen al terrorismo de Estado de la dictadura. Existen numerosos testimonios del interés de López Rega, apodado “el Brujo", por el ocultismo. Son esas historias las que retoma Valenzuela en la novela, entrecruzando así elementos que aprecen como fantásticos o propios de la imaginación de la ciencia-ficción, pero provienen de referencias y hechos históricos (sin ir más lejos, el recorrido del cadáver embalsamado de Eva Perón). De hecho, es difícil clasificar esta historia dentro de un género determinado; si nos atenemos a las definiciones más estrictas de la ciencia-ficción, la mayoría de sus elementos están ausentes ya que no hay viajes espaciales o en el tiempo, explicaciones científicas, ni desarrollos tecnológicos. Pero si tenemos en cuenta las definiciones más amplias, menos temáticas, se trata aquí de elaborar un universo de realidades alternativas, de una distopía contemporánea a los echos históricos, de una elaboración de la pregunta “¿qué pasaría si López Rega quisiera apoderarse del mundo?” Pues de eso se trata la historia: de los delirantes planes del Brujo de dominar el mundo desde su oculto reino en los esteros pantanosos del interior del país. La narración apela a un lenguaje elusivo y alegórico, con una fuerte carga simbólica, y construye un personaje cuasi monstruoso que atraviesa procesos de descomposición de su identidad social, política y sexual a través de un grotesco viaje iniciático. En estas y en otras obras se conjugan elementos mágicos y sobrenaturales

5 José López Rega (Buenos Aires, 1916-1989), apodado el "Brujo" por su interés en el esoterismo y las ciencias ocultas, se vincula con Juan Domingo Perón desde 1965, convirtiéndose en su secretario privado y ejerciendo gran influencia sobre Perón y su esposa María Estela Martínez (Isabel). Entre 1973 y 1975 fue Ministro de Bienestar Social en Argentina.

6 Juan Domingo Perón (Lobos, 1895-1974), militar, político y presidente argentino. Fue elegido en tres ocasiones: 1946-1952; 1952-1955 (depuesto por el golpe militar autodenominado "Revolución libertadora”); y, tras su exilio, en 1973 ejerció el mando hasta su fallecimiento; fue sucedido por su esposa.

\footnotetext{
(3) Revista Iberoamericana, Vol. LXXVIII, Núms. 238-239, Enero-Junio 2012, 247-258 ISSN 0034-9631 (Impreso) ISSN 2154-4794 (Electrónico)
} 
con claras referencias a figuras centrales de la política argentina, para realizar una aguda crítica social que abarca lo político y lo sexual como manifestaciones conjuntas del poder. Esta crítica se manifiesta a través de un lenguaje cercano a lo coloquial que usa la ironía, la inversión de los lugares comunes y los estereotipos, desarticulando las concepciones convencionales de los roles y las relaciones de los sexos. Las máscaras y el cuerpo representado en su manifestación más grotesca anulan las diferencias sexuales y trastocan la identidad de los personajes y las estructuras sociales. Aquí, el Brujo construye sus delirantes planes de dominación a partir de una característica corporal que él transforma en elemento sobrenatural definitorio de su poder: un tercer testículo que él feminiza, llamándolo Estrella, hermana y esposa a la vez. Esa característica lo aparta de la humanidad, se convierte en fuente de su supuesto poder, inspiración para la construcción de una pirámide a partir de la cual dominaría el mundo, y finalmente causa de su propia destrucción en un río/hilo de sangre. Fernando Reati señala respecto a este personaje que "su sexualidad es tan perversa como su política, porque niega el derecho a la existencia del Otro” (228). El movimiento inverso se produce con la traslación del poder fálico del miembro sexual masculino al dedo cortado al cadáver de la Santa, la Capitana (referencia indirecta pero evidente a Eva Perón, y al hecho real de que su cadáver fue así mutilado), el otro elemento dotado de poder fecundante para los planes de autotrascendencia del Brujo, que culminarán con su autodestrucción.

El caos político y la violencia social sólo pueden ser trascendidos, para bien o para mal, por la deconstrucción del sistema de géneros, la disolución de las identidades sexuales fijas y estables, disolución que se manifiesta en el discurso a través de los procedimientos de la ironía, el grotesco, la máscara como imagen de la confusión y la repetición de la identidad. Valenzuela desarrolla esta historia y sus dos niveles en un lenguajeágil, cotidiano, muy cercano a la conversación espontánea, pero al mismo tiempo desarticula sus lugares comunes, produce un efecto humorístico transformando las frases hechas de la lengua cotidiana en algo inesperado; a través de esas transformaciones genera una visión crítica de la sociedad, del poder que se ejerce sobre las personas a través de ese lenguaje.

\section{César Aira, El CONGReso de literatura, 1997}

Aira se acerca en esta novela al género de la ciencia-ficción con premisas propias de la tradición central del género, pero en una versión más esquemática e irónica. La ironía no va dirigida a la ciencia-ficción, sino a las instituciones literarias y sus múltiples jerarquías y clasificaciones que abarcan obras, instituciones, prácticas y personas.

El protagonista es escritor, traductor, aventurero, inventor y científico loco. Ha construido una máquina de clonación, y su idea para dominar el mundo es clonar a un genio: elige para ello al escritor mexicano Carlos Fuentes, a quien verá en un congreso.

\footnotetext{
Revista Iberoamericana, Vol. LXXVIII, Núms. 238-239, Enero-Junio 2012, 247-258 ISSN 0034-9631 (Impreso)

ISSN 2154-4794 (Electrónico)
} 
Sus planes, sin embargo, no resultan según lo previsto. En lugar de clonar a Fuentes, clona una célula de su corbata de seda, creando un ejército de gusanos azules que asola la ciudad de Mérida, Venezuela. La idea de invención, verbal, literaria, científica, atraviesa el texto con el cuestionamiento implícito en los mecanismos de la traducción y la clonación que ponen en cuestión el vínculo entre creación y repetición.

Lo mismo sucede con los intereses amorosos del protagonista-narrador, las únicas mujeres que aparecen en el relato. Todas remiten unas a otras, como sucesivas copias o imágenes en negativo, todas derivando del primer amor infantil y remitiendo a la mujer elusiva, oculta, invisible. En realidad, el único “sujeto” pleno que aparece en la novela es el protagonista-narrador, confirmando así, aunque en un contexto irónico, el arquetipo del genio faústico para quien la mujer es una creación, una proyección de sí mismo, como aparece reiterado en la obra teatral por él escrita y representada en el congreso, que recrea el mito del Génesis y la creación de la mujer a partir de una costilla de Adán.

ANGÉLICA GORODISCHER, KALPA IMPERIAL I Y II 1983-84; BAJO LAS JUBEAS EN FLOR, 1973

Angélica Gorodischer es una escritora cuyo nombre de autor se identifica desde sus primeras obras, publicadas a fines de la década del sesenta, con la ciencia-ficción. Opus dos (1967) presenta todas las características de la ciencia-ficción norteamericana de la época, presentando una serie de episodios situados en un futuro distante y posapocalíptico donde las relaciones raciales se han invertido, y con referencias indirectas que sitúan partes de la historia en lo que había sido Argentina.

Si bien Gorodischer participa de los debates en torno a los problemas de género y escritura y es ferviente defensora del lugar de la mujer en la literatura, en sus primeras obras no problematiza de manera central la construcción de las identidades de género a la manera en que lo hace con la raza o el poder. Sin embargo, podemos encontrar elementos que apuntan en esa dirección en algunos de sus relatos. En Bajo las jubeas en flor, los cuentos presentan rasgos más específicos de la ciencia-ficción: viajes espaciales, diferentes planetas, futuros lejanos. En el que es talvez el más logrado, "Los embriones del violeta”, la tripulación de una nave abandonada en un planeta extraño, compuesta sólo por hombres, encuentra unas zonas de color violeta que les permiten materializar todo lo que desean. Pero no logran materializar mujeres: el problema es que para crear algo deben "convertirse en" o "pensar como" eso que desean. Y aparentemente, para todos esos hombres, la mujer es un "Otro" tan ajeno que la tarea de materializarlas es imposible. En este relato (recordemos, de la década del setenta) persiste una concepción binaria y biológica de las identidades sexuales: para reemplazar a las impensables mujeres, los hombres acuden a reconstruirlas mediante procedimientos quirúrgicos, pero siguen sosteniendo ante los recién llegados que "no hay mujeres" en el planeta. Aunque haya bailarinas, nodrizas, criadas, etc., la definición de "mujer" sigue siendo esencial, y esencialmente anatómica o biológica.

Revista Iberoamericana, Vol. LXXVIII, Núms. 238-239, Enero-Junio 2012, 247-258
ISSN 0034-9631 (Impreso) 
Una obra posterior, Kalpa Imperial, es comúnmente incluída entre sus obras de ciencia-ficción, pero son relatos en los que la ciencia y la técnica están ausentes, no tienen una ubicación temporal o espacial precisa o siquiera sugerida. Se trata de las historias de un narrador oral que, como lo explica uno de los últimos relatos, es llamado por una emperatriz para contarle la extensa historia de un imperio vagamente oriental, en sucesivos ciclos de construcción, decadencia y reconstrucción. Entre ellos, las mujeres que llegan a detentar el poder imperial se destacan justamente por ejercerlo, no en tanto mujeres, sino a partir de la búsqueda del saber, el saber de la historia, el de conocimiento de los detalles que configuran la identidad de su nación y su pueblo.

Otro cuento, esta vez de Las repúblicas, de 1991, "El inconfundible aroma de las violetas silvestres”, se sitúa otra vez en un futuro, esta vez centrado en lo que había sido el territorio argentino, disgregado en varias naciones menores (de allí el título del libro), en un mapa internacional invertido, donde los disgregados Estados Independientes de Norteamérica son una nación de segundo orden y Bolivia, Paraguay y Madagascar son los países centrales. El relato cuenta la historia del descubrimiento de una nave espacial en "el Rosario" y el consiguiente viaje hasta los límites del universo, tripulada por una "astronauta argentina". Esto desata comentarios de asombro y extrañeza en todo el mundo, desde la emperatriz de la Santa Rusia al pueblo de Madagascar, extrañeza dirigida tanto al sexo de la astronauta ("no es una mujer, es un transexual”, sostiene "la más puritana de las pantallas informativas" [104]) como al lugar desde el cual se produce el viaje. Sin embargo, nada de esto tiene consecuencias, ni globales, ni locales, ni sociales salvo para la astronauta en cuestión; y aún así, se trata de consecuencias íntimas que no afectan el resto de su vida que transcurre por los normales carriles del matrimonio y la maternidad.

El recorrido por las obras seleccionadas muestra cómo los usos del género de cienciaficción apuntan, con procedimientos y elementos muy variados, a abrir las posiblidades narrativas de un cuestionamiento de las identidades nacionales, políticas y de género. Así, en Pubis Angelical, la utopía de la superación de la dominación sexual propuesta desde el título implica también en el relato final la única posibilidad de superación de la dominación y los conflictos sociales que llevan a confrontaciones armadas, mientras que en La ciudad ausente la persistencia de los arquetipos femeninos primarios se conjuga con la imposibilidad de proponer una salida efectiva a la dominación ejercida por el poder de un estado que controla la realidad controlando sus relatos; la única posibilidad de resistencia es el incesante relato solitario de una mujer convertida en máquina, relatando una y mil versiones de la historia sin que nadie la escuche, como una Casandra maquínica. En Cola de Lagartija volvemos a encontrar una propuesta de superación de las diferencias y jerarquías de género, enlazando sexualidad y política en los efectos de esa anulación de las diferencias que se construye como contrapartida de la anulación del otro. Gorodischer y Aira son los que toman y desarrollan más los rasgos específicos de la ciencia-ficción, poniendo en juego en ambos casos un nombre

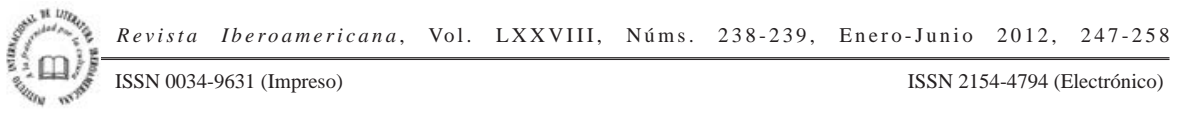


de autor, el primero identificado con este género literario, y el segundo con el uso paródico de los géneros populares. En Aira, en especial, resulta relevante la discusión implícita con las instituciones académicas, con la definición de originalidad, de creación que encuentra en la imagen de la clonación y el relato bíblico de la creación del hombre y la mujer, un punto de partida para el desarrollo de la ironía y el cuestionamiento de esas nociones.

Este recorrido sugiere desde mi perspectiva que el uso no normativo, no restrictivo de los elementos que caracterizan a un género literario multiplica las posibilidades significativas de una obra literaria; cuestionar las formas genéricas permite cuestionar sentidos establecidos en esas formas, hacer evidentes las conexiones entre los diferentes niveles significantes y aspectos aparentemente diferenciados del mundo de la ficción y del mundo de la supuesta "realidad".

\section{BiBLIOGRAFÍA}

Evans, Christopher. Writing Science Fiction. Londres: A \& C Black, 1988.

Genette, Gérard. Introduction à l'architexte. Paris: Éditions Du Seuil, 1979.

Greenberg, Martin y Isaac Asimov, eds. Cosmic Critiques: How and Why Ten Science Fiction Stories Work. Comentarios por Ansen Dibell. Cincinnati: Writer's Digest Books, 1990.

Jackson, Rosemary. Fantasy: The Literature of Subversion. Londres: Methuen, 1981. Jameson, Fredric. Documentos de cultura, documentos de barbarie. Madrid: Visor, 1989.

Jauss, Hans Robert. Towards an Aesthetic of Reception. Minneapolis: U of Minnesota P, 1982.

Nicholls, Peter. Encyclopedia of Science Fiction. Londres: Orbit/Little, Brown and Company, 1993.

Pringle, David. Science Fiction: The 100 Best Novels. Londres: Xanadu, 1985.

Prucher, Jeff. Brave New Words: The Oxford Dictionary of Science Fiction. Nueva York: Oxford UP, 2007.

Reati, Fernando. Postales del porvenir. Buenos Aires: Biblos, 2006.

Stableford, Brian, John Clute y Peter Nicholls. "Definitions of SF”. Encyclopedia of Science Fiction. John Clute y Peter Nicholls. Londres: Orbit/Little, Brown and Company, 1993.

\footnotetext{
Revista Iberoamericana, Vol. LXXVIII, Núms. 238-239, Enero-Junio 2012, 247-258 ISSN 0034-9631 (Impreso) 